\title{
A POESÍA ROSALIANA NO CANON LITERARIO DO SEU TEMPO
}

José Manuel González Herrán

Universidade de Santiago de Compostela

doi: 10.17075/rcsxxi.2014.31

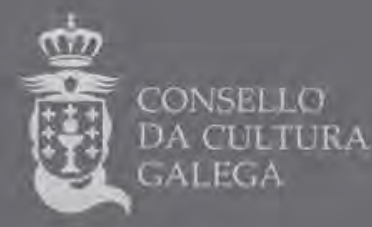



Álvarez, R. / A. Angueira / M. C. Rábade / D. Vilavedra (coords.) (2014): Rosalía de Castro no século XXI. Unha nova ollada, Santiago de Compostela, Consello da Cultura Galega. doi:10.17075/rcsxxi.2014. pp. 589-602

Nesta sección sobre «Rosalía no canon literario do seu tempo», ocupareime da súa poesía, desde a perspectiva da literatura española. Para axustarme ó espazo asignado, e tamén porque é a época que mellor cońezo, limitarei a miña análise ó período inicial nese proceso canonizador ${ }^{1}$, tentando mostrar como a recepción coetánea e a inmediatamente posterior foron asignando á poesía rosaliana (tanto en galego como en castelán) un determinado lugar no canon da poesía hispánica do XIX; acaso poida espertar o interese do lector amosando como algúns dos problemas (metodolóxicos, historiográficos, estéticos, interpretativos, ideolóxicos, políticos, lingüísticos, etc.) que condicionaron ese proceso de canonización se formularon xa desde o seu inicio.

Un proceso que se caracteriza por unha notable complexidade en que incidiron factores e condicionantes moi diversos; Marina Mayoral, nas páxinas introdutorias ó seu xa clásico libro, expresábao nestes termos: «Durante muchos años el silencio de la crítica envolvió la obra de Rosalía de Castro [...]. Cuando [la crítica] volvió los ojos hacia ella, el proceso había llegado a su fin: Rosalía era -es- ya un mito. Silencio y mitificación han hecho de ella una figura mal conocida» (Mayoral 1974: 15). Os corenta anos transcorridos desde aquela non melloraron substancialmente a situación, lonxe aínda de estar totalmente afianzada. Non pretendo dicir, nin moito menos, que Rosalía, como poeta, non acadase a consagración canónica que a sitúa nun dos lugares privilexiados na lírica europea de todos os tempos. Pero parece indiscutible que ese lugar non é o mesmo, nin ocupa o mesmo rango, segundo que atendamos á súa obra en galego ou en castelán: ser a figura máxima, universalmente aceptada e apreciada (aínda que non unanimemente entendida, interpretada ou explicada) nas letras galegas; ou representar, con Gustavo Adolfo Bécquer, o comezo da modernidade na poesía española, cando aínda non rematara o século dezanove. E deixo á marxe a súa obra en prosa, que — sen perxuízo da reconsideración que nos últimos tempos se

1 Ocupeime da recepción da poesía rosaliana, entre 1864-1960, en González Herrán 1985 e en González Herrán 1999. A recompilación máis completa é a de Alonso Montero 1985, de onde proceden varias das mostras que aquí citarei. 
lle vén dedicando ${ }^{2}$ - coloca a nosa autora nun rango moi secundario, respecto ós seus coetáneos Alarcón, Valera, Pereda, Galdós, Pardo Bazán ou Clarín.

No estudo que antes lembrei, advertía Mayoral:

Rosalía escribe en gallego la mayor parte de su obra poética, y el emplear una lengua que no es la oficial de la nación y el haber sido la primera que la usó con auténtica categoría literaria tras un silencio secular, fue un grave inconveniente para la crítica. Hoy nos parece ridículo, pero todavía se sigue separando en los estudios críticos su obra castellana de su obra gallega, como si no nacieran de la misma fuente. Pero no sólo escribe en gallego, sino que habla de Galicia. No es una poeta puramente lírica, sino que posee una fuerte tendencia social: no es sólo la poeta quien se refleja en sus versos; es también un pueblo (Mayoral 1974: 15).

Consideremos, pois, en primeiro lugar, o factor lingüístico, que condicionou de maneira moi determinante a canonización da poesía rosaliana; e non só pola diferente valoración que antes salientei, senón porque a súa recepción crítica tamén se viu afectada polo mesmo. Non é infrecuente o caso de críticos e estudosos que, ademais de restrinxir a súa lectura a unha ou outra parcela — segundo o idioma - da súa obra, establecen conclusións valorativas derivadas de iso: así o facía, por exemplo, Juan Barcia Caballero cando xulgaba en 1885 o libro acabado de aparecer En las orillas del Sar: «A pesar del indisputable mérito que este libro encierra $[\ldots]$ he de confesar que si a escoger me dieran entre los versos de la autora, preferiría sin duda los gallegos [...] [por] la mayor dulzura y sentimiento, que son el distintivo de las rimas gallegas de nuestra poetisa» (en Alonso Montero 1985: 281). O mesmo opinaría, bastante máis tarde (1957), Luis Cernuda: "quizá los mejores [versos] de Rosalía sean los que escribió en gallego» (en Alonso Montero 1985: 136). Pero Unamuno — sempre á contra— dixera en 1912: «prefiero estas rimas castellanas a las gallegas [...]. Son estas más liricas, más personales, más universales, en fin» (en Alonso Montero 1985: 295).

José María de Cossío, acaso o mellor coñecedor e historiador da poesía española entre 1850 e 1900, escribe no seu fundamental panorama: «La personalidad

2 Entre as obras recentes, cómpre salientar, polo suxestivo das contribucións que reúne, o volume colectivo de González Fernández e Rábade Villar (2012). 
poética de Rosalía de Castro exige para ser estudiada totalmente la consideración de sus versos en gallego: Cantares gallegos y Follas novas son, acaso, más importantes libros que los escritos en castellano, especialmente el primero» (Cossío 1960: 1054). Chamo a atención sobre esa advertencia (a súa valoración preferente por Cantares gallegos), porque non só o factor lingüístico incide na canonización que me vén ocupando: as notables diferenzas - temáticas, formais, estilísticas, métricas: de formulación poética, en suma) - entre o libro de 1863 e os de 1880 e 1884 determinaron a aceptación de lectores e críticos, moitos dos cales prefiren «unha Rosalía» á «outra». Ben é verdade que cada vez se afianza máis a opinión que defende a unidade total da lírica rosaliana; como xa o facía en 1937 o catalán Guillermo Díaz-Plaja: «es imposible separar en la obra poética de Rosalía [...] su producción castellana de la gallega; las funde un mismo espíritu» (en Alonso Montero 1985: 106).

O factor lingüístico, como condicionante do proceso canonizador que veño comentando, está intimamente vinculado ós ideolóxico-políticos, que seguen incidindo tanto na súa interpretación como — consecuentemente- na súa valoración. Claude Poullain díxoo de maneira categórica (talvez demasiado), ó referirse a «la doble perspectiva de Rosalía. Los gallegos y los no gallegos tienen una visión diferente de su obra, y no puede ser de otro modo" (en Alonso Montero 1985: 444). Pero a distinción non sempre é tan clara; especialmente cando se discute ou nega a condición de galegos a determinados lectores.

Como exemplo dese tipo de interferencias ideolóxico-políticas, recordarei aquí un episodio que só enunciarei, pois abordalo en toda a súa complexa dimensión ocuparía máis espazo do que se me ten concedido. Estoume referindo ó que un recente artigo, así titulado, considera —ó meu xuízo, excesivamente— «un discurso clave no proceso de canonización da obra de Rosalía» (Pardo Amado 2010): o pronunciado por Emilia Pardo Bazán na velada necrolóxica organizada pola Reunión Recreativa do corunés Círculo de Artesanos o 2 de setembro de 1885; discurso que a súa autora titulou — dato que semella esquecerse— «La poesía regional gallega» (Pardo Bazán 1973: 671-689), pois, aínda que Rosalía fose protagonista e destinataria da homenaxe, a súa obra non foi obxecto único «mais si preferente» da disertación. A cal, como dixen no meu traballo «Presencia de Curros y doña Emilia, cincuenta años después», 
en lugar de ser considerada como lo que es, una muestra del profundo conocimiento, riguroso análisis e indudable aprecio de Pardo Bazán por la poesía gallega, ha quedado, a causa de lecturas parciales — en el doble sentido del término- como la más grave prueba de cargo contra la Condesa, aún no indultada de sus graves delitos contra la literatura gallega [...] Discurso, sobre el que — me temo— siguen repitiéndose los mismos tópicos acuñados por Murguía (González Herrán 2004: 133).

Afortunadamente, hai quen soubo eludir tales tópicos: así, Fernando Cabo, cando, no seu monumental libro El lugar de la literatura española, opina que esa lección pardobazaniana «fue posiblemente la primera revisión global del renacimiento literario gallego», que "no se manifestó con hostilidad abierta hacia la literatura en gallego» e que «muchas de sus apreciaciones resultaron notablemente penetrantes»(Cabo Aseguinolaza 2012: 476 e 479).

Pero é que, como sinalei no meu artigo antes citado, "el elogio fúnebre a la cantora del Sar, que a su viudo le pareció mezquino, [...] objetivamente considerado, era mucho más de lo que la mayoría de sus contemporáneos y coterráneos» escribisen sobre ela (González Herrán 2004: 133). En todo caso, agora impórtame a apreciación da escritora coruñesa, para quen a compostelá-padronesa (permítaseme ese mixto xentilicio) era a principal artífice do Rexurdimento. "De los Cantares [gallegos] — di- procede la segunda época del renacimiento gallego, la segunda generación de poetas»; entre os que menciona a Curros, Lamas Carvajal, Losada, Muruais, Pondal, Ballesteros, De la Iglesia... (Pardo Bazán 1973: 684).

Esa explícita mención do primeiro poemario rosaliano e a súa declarada preferencia por el («lo mejor que Rosalía ha producido y lo más sincero de la poesía gallega [...] podrán las innovaciones [refírese ás métricas] de Follas Novas revelar más ciencia, pero no mayor tino», Pardo Bazán 1973: 682) fixeron da futura Condesa — aínda non o era entón- principal responsable no proceso de adscrición rexionalista da cantora do Sar. Pero conviría advertir que, con iso, dona Emilia se facía eco dun ditame histórico-crítico moi xeneralizado daquela, formulado, entre outros, por quen era tido como principal mestre e árbitro nas letras hispánicas, Marcelino Menéndez Pelayo. 
En efecto, malia que o seu nome nunca se cite verbo de Rosalía (agás para reprocharlle —o primeiro, Azorín, e con toda xustiza ${ }^{3-}$ que se esquecese da nosa poeta cando antologou os do século XIX), quero lembralo aquí, e non só por razóns de vecińanza. Polo que sabemos, a primeira noticia que Marcelino tivo de Rosalía recibiuna do seu mestre e paisano Gumersindo Laverde Ruiz (catedrático no Instituto de Lugo entre 1870 e 1873; logo, na Universidade de Valladolid; e na de Santiago, ata a súa morte, en 1890). Nunha carta a Menéndez Pelayo, datada en Valladolid en outubro de 1874, inclúe nunha extensa relación de escritoras españolas contemporáneas a «Rosalía Castro de Murguía, que tradujo poesías de Aguilera al gallego» (Menéndez Pelayo, 1982: 114): curiosa mostra do que un moi informado erudito da época podía dicir da nosa escritora.

Malia a tan deficiente información, é seguro que Menéndez Pelayo a completou xa que nun artigo na Revista Cántabro-Asturiana (1877), dedicado a un poeta cántabro falecido pouco antes, Evaristo Silió, para situar e caracterizar a súa produción lírica, formula unha proposta sobre a existencia dunha corrente ou escola poética que denomina septentrional, propia dalgúns poetas románticos - e posrománticos - asturianos, galegos, leoneses, cántabros, entre os que expresamente menciona o berciano Enrique Gil, os galegos Pastor Díaz, Aurelio Aguirre e Rosalía de Castró . Estes serían os trazos que, ó seu xuízo, definen a esa escola:

Sońadores y meditabundos los [poetas] septentrionales, distínguense por lo vago y aéreo del fondo de sus concepciones, por la melancolía intensa y profunda que casi siempre les anima, por su afición extremada a la parte sombría, nebulosa y triste de la naturaleza, que produce en ellos graves pensamientos y solemnes meditaciones. La escuela del Norte es creyente como todas las escuelas peninsulares, pero la expresión del sentimiento religioso [...] propende a abstracciones y es siempre subjetiva, gustando sobre todo de cantar la triste peregrinación del hombre por este valle de lágrimas, las agitaciones y tormentos de la conciencia, el dolor y la resignación que expían y llegan a borrar el pecado. Las vagas inquietudes del alma, el anhelo y la sed de lo infinito suelen ser, así mismo, asunto de esta poesía (Menéndez Pelayo 1942: 245-246).

3 «tampoco [...], en 1908, logró penetrar Rosalía en la no menos lamentable colección de líricos — Las cien mejores poesías - formada por Menéndez y Pelayo» (Azorín 1913; en Alonso Montero 1985, 98).

4 A seguir, resumo ou parafraseo o meu artigo González Herrán 2012. 
Como xa sinalou Cossío, a idea menendezpelayiana de caracterizar os poetas do norte en oposición ós do sur xa fora proposta polo citado Laverde nun ensaio de 1868 sobre a poetisa asturiana Robustiana Armińo, onde escribía: «La organización y carácter personal del que escribe, la influencia de la naturaleza y de la sociedad que le rodea ¿no son datos y antecedentes que deben tenerse en cuenta al apreciar el tono y sentido de sus obras? ¿Podrán ser risueñas como en Andalucía las inspiraciones que brotan en las montañas de Asturias, bajo un cielo nebuloso y ante un mar bravío agitado por continuas borrascas?» (Laverde Ruiz 1968: 23).

Quizais esta digresión erudita pareza impertinente (e disparatada a idea que emparella a Rosalía con aquela esquecida poetisa asturiana), pero eses testemuños poden exemplificar ben como no seu tempo a lírica rosaliana foi caracterizada como mostra dunha certa poesía regional (do norte, neste caso). Caracterización que, dalgún xeito, recolleu Cossío (aínda que nunca incluíse a Rosalía nesa escola), cando dedicaba unha epígrafe a «la poesía norteña» no seu libro de 1960: «Llámesela escuela, tendencia, o manera, es lo cierto que los poetas del norte de España tienen algunas características comunes que autorizan a hablar de una poesía norteña, diferenciada de la que nace en otros climas y otras regiones españolas»; e engade unha precisión que coido que é pertinente recordar aquí: «la caracterización general de ese tono melancólico que Menéndez Pelayo y Laverde atribuyen a los poetas norteños ha de diferenciarse en las diversas regiones, aunque siempre con ese común denominador» (Cossío 1960: 968).

Descartada - por escasamente aceptable hoxe en día, malia que no seu tempo tivese defensores - a súa adscrición a esa "poesía regional norteña», segue vixente outro debate histórico-crítico, a propósito da situación da poesía rosaliana no complexo panorama de tendencias, correntes, modalidades, escolas... da poesía hispánica na segunda metade do dezanove. Se é que seguimos admitindo esa escisión que afasta os románticos dos que non o son, definidos por contraste con aqueles (posrománticos, románticos serodios, románticos demorados) ${ }^{5}$, recordemos o que escribiu en 1940 o primeiro historiador do movemento romántico español, Edgard Allison Peers: «Estaba reservado a los románticos posteriores, que

5 "A etiqueta de pos-romantismo ou de romantismo tardío, inda ancorada nunha concepción ahistórica do romantismo, é decididamente inadecuada», escribe Alonso Nogueira (1999: 52) a propósito de Rosalía. Pola súa parte, desde outra perspectiva e con outros presupostos, tamén Rodríguez (2011: 492-503) rexeita a etiqueta de «romántica rezagada» para a nosa autora. 
nunca habían respirado aire de seudoclasicismo, atreverse a ser románticos del todo y por completo. Tal fue Rosalía de Castro de Muguía» (en Alonso Montero 1985: 180).

Tamén aquí pode ser oportuno acudir ós xuízos inmediatos para amosar como os seus primeiros lectores poñían os versos de Rosalía en relación cos dos seus coetáneos. Se os seus primeiros libros (La flor, A mi madre) foron adscritos entón ó ronsel de Espronceda (o seu mestre, segundo Murguía na recensión de La flor en 1857, tan madrugadora como oportuna, en Alonso Montero 1985: 171-176), Cantares gallegos foino — acaso por moitos que só se fixaron no título- ó modelo de Antonio de Trueba, no seu El libro de los cantares (1852); aínda que houbo quen —como Ruiz Aguilera - aduciu un nome foráneo, o escocés Robert Burns (en Alonso Montero 1985: 209). Os referentes de Follas Novas e En las orillas del Sar foron —con notoria unanimidade- Heine e Bécquer; aínda que iso non sempre fose un eloxio: sirva como mostra o que lle escribe Laverde a Menéndez Pelayo nunha carta desde Santiago, en novembro de 1880, na que di estar lendo Follas novas: a súa autora parécelle «tocada del pesimismo escéptico de Heine y Bécquer, que descorazona. Estos suspirillos germánicos son el reverso de las anacreónticas de antaño, aunque igualmente monótonos» (Menéndez Pelayo 1983: 398). Non moi diferente era a opinión de Manuel Tamayo y Baus, cando aludía ás «nebulosidades metafísicas, que generalmente proceden del prurito de imitar a la escuela germánica» (en Alonso Montero 1985: 287).

A influencia de Heine en Rosalía e mais en Bécquer así como o papel de cada un deles como indutor do outro á lectura do poeta alemán foron amplamente debatidos e non os tratarei aquí. Aínda que si lembrarei o dato que deixou escrito Víctor Said Armesto nas notas para o seu inédito estudo sobre a vida e obra de Rosalía (tan sabiamente utilizadas por González Besada para o seu discurso de 1916, como demostrou Álvarez Ruiz de Ojeda de maneira convincente): «Bécquer conoció las poesías de Heine por el libro en francés que Rosalía le prestó. Era [o poeta sevillano] admirador apasionado de Rosalía [...] había leído todas sus producciones gallegas, así las publicadas como varias inéditas [y] muchas de las castellanas» (citado en Álvarez Ruiz de Ojeda, 2011: 25).

A comparanza entre Rosalía e Bécquer (tópico crítico moi vivo no seu tempo, repetido logo, pero hoxe sometido a revisión) apoiouse, ás veces, na semellanza —máis aparente que substancial— das súas respectivas innovacións métricas: 
aspecto que boa parte da crítica inmediata notou como censura, pero que a posterior valorou máis positivamente. No seu ditame académico sobre o libro de 1884, Tamayo reprocháballe «deslices artísticos» e «extravagancias de forma» (en Alonso Montero 1985: 287), aludindo, sen dúbida (aínda que non o declarase expresamente), ó que outro crítico coetáneo, o galego Waldo Álvarez Insua (no Eco de Galicia, da Habana), consideraba "cierta anarquía métrica», desculpada como "peculiar en los verdaderos genios» (en Alonso Montero 1985: 277). Pola súa banda, o hoxe esquecido Máximo Leyes Pose (que rescatou Fermín BouzaBrey en 1961) facía unha recensión de Las orillas del Sar nun xornal estudantil compostelán, El Tricornio, advertindo que a súa autora «ha roto las cadenas de la armonía rítmica, el compás de la cantidad prosódica», o que —ó seu xuízoproducirá unha verdadeira revolución nas letras españolas (citado en Bouza-Brey Trillo 1992: 144). Máis interesante paréceme a sagaz intuición doutro coetáneo, o médico compostelán Barcia Caballero, que aludía — sen nomealo- a Wagner para xustificar as novidades métrico-estróficas do mesmo libro:

A semejanza de esa música alemana que, quizá sobrado grande para caber en las estrecheces del pentagrama, amenaza a cada paso con destruir la armonía a fuerza de atrevimientos, así estos versos son, más que artificios literarios, quejas espontáneas de un alma dolorida; saltan por encima de todas las reglas y se forjan una medida y una rima que concuerde con la grandeza de su amargura (en Alonso Montero 1985: 279-280).

Esa valoración positiva conságrase co artigo de Díez Canedo en La Lectura, en 1908, que pondera os «metros inusitados y combinaciones nuevas [...] combinaciones llenas de armonía nueva», as súas «extraordinarias adivinaciones métricas», que fan de Rosalía «una precursora» (en Alonso Montero 1985: 289-292); non di de que, pero entendemos que alude á daquela triunfante lírica modernista.

Un último factor quero mencionar no proceso canonizador da lírica rosaliana: a súa dimensión feminina —ou feminista—, tan preferentemente atendido pola crítica actual, e que non ignoraron algúns dos seus primeiros lectores, malia que de maneira moi diferente a como hoxe en día o facemos Así, a paternalista - e un punto ofensiva - argumentación que emprega Tamayo y Baus, cando recomenda no seu informe académico «que el Ministerio de Fomento adquiera algunos ejemplares para las bibliotecas públicas de En las orillas del Sar [...] por 
ser poesías de una señora, y por el carácter benéfico que la legislación protectora de las publicaciones literarias en realidad tiene» (en Alonso Montero 1985: 287). $\mathrm{Ou}$ os discutibles argumentos antropolóxico-étnicos esgrimidos por César Barja en 1926: «es el lirismo gallego [...] un lirismo del todo femenino. Femeninos son sus temas, femeninos son sus acentos. Y ese lirismo femenino es [...] la modalidad espiritual de la raza gallega, del paisaje y de la tierra, por naturaleza líricos. Lirismo, lirismo femenino: eso es Galicia, y eso es Rosalía de Castro. El triunfo de Rosalía es el triunfo del lirismo femenino, es decir, la revolución plena y el triunfo decisivo del alma regional» (en Alonso Montero 1985: 105). Con máis sagacidade apuntábao Said Armesto (e repetiu González Besada 1916) cando relacionaba a voz feminina dos cantares rosalianos co eu lírico das cantigas medievais (citado en Álvarez Ruiz de Ojeda 2011: 29).

Quedan sen tratar varias cuestións de interese: o papel de Murguía na primeira canonización (nun sentido do termo que desborda o estritamente académico que aquí veño empregando) da obra —e a persoa— da súa esposa (Alonso Nogueira 1999); a incidencia en tal proceso das tensións — máis ou menos latentes— do campo literario que entón se estaba delimitando, coas súas implicacións sociais e políticas (Alonso Nogueira 1999); os factores de índole editorial (valla dicir económico-comerciais) que determinaron a súa difusión e recepción iniciais, tanto aquí como na Galicia emigrada (ver neste mesmo volume o artigo de Santiago Díaz Lage: «Vivir, escribir, publicar: Rosalía de Castro no sistema editorial do seu tempo»)... Parece prudente deixalo para outra ocasión. 


\section{REFERENCIAS BIBLIOGRÁFICAS}

Álvarez Insua, Waldo (I 884): Recensión de En las orillas del Sar, El Eco de Galicia, A Habana, 109 (27-VII-1884) e 112 (17-VIII-1884); en Alonso Montero, I985, 276-278.

Álvarez Ruiz de OJeda, Victoria (20 I I): «Víctor Said Armesto, Rosalía de Castro e Manuel Murguía (con Augusto González Besada ao fondo)", Revista de Estudos Rosalianos, 4, 15-126.

Alonso Montero, Xesús (1985): En torno a Rosalía, Madrid, Júcar.

Alonso Nogueira, Alejandro (I999): «A invención do escritor nacional. Rosalía de Castro: a poeta e a súa patria», en Rosario Álvarez / Dolores Vilavedra (eds.), Cinguidos por unha arela común. Homenaxe ó profesor Xesús Alonso Montero, Santiago de Compostela, Universidade, II, 45-63.

Azorín [José Martínez Ruiz] (I913): «Rosalía de Castro», en Clásicos y modernos, Madrid, Renacimiento; en Alonso Montero, I985, 97-IOI.

Barcia Caballero, Juan (I885): [«artículo que figura en las dos ediciones de En las orillas del Sar de 1909. Se consigna esta fecha: febrero de 1885»]; en Alonso Montero, 1985, 463.

BarJa, César (1926): «En torno al lirismo gallego del siglo XIX», Smith College Studies in Modern Languages, [Northampton, Mass.], VII, 2-3.

Bouza-Brey, Fermín (1961): «Manuel Barros, escritor emigrado, amigo de Rosalía, y los orígenes del libro En las orillas del Sarn, Cuadernos de Estudios Gallegos, XVI:49, 218-239; recollido en Fermín Bouza-Brey Trillo (1992), Artigos rosalianos, Santiago de Compostela, Xunta de Galicia.

Cabo Aseguinolaza, Fernando (2012): Historia de la literatura española 9. El lugar de la literatura española, Barcelona, Crítica.

Cernuda, Luis (1957): «Rosalía de Castro (1837-1885)», en Estudios sobre poesía española contemporánea, Madrid, Guadarrama; en Alonso Montero, I985, I 3 I-I 39.

Cossío, José M. a de (1960): Cincuenta años de poesía española (1850-1900), Madrid, Espasa-Calpe.

Díaz-Plaja, Guillermo (1937): La poesía lírica española, Barcelona, Labor.

Díez Canedo, Enrique (1908): «Una precursora» [«publicado en La Lectura, Madrid (1908), se reproduce en las ediciones de En las orillas del Sar de 1909»]; en Alonso Montero, I985, 463.

González Besada, Augusto / Jacinto Octavio Picón (I916): Discursos leídos ante la Real Academia Española en la recepción pública del Excmo. Señor D. Augusto González Besada el día 7 de mayo de 1916, Madrid, Imprenta Clásica Española.

González Fernández, Helena / María do Cebreiro Rábade Villar (eds.) (2012), Canon y subversión. La obra narrativa de Rosalia de Castro, Barcelona, Icaria.

González Herrán, José Manuel (1985): «Palabras sobre Rosalía: Un diálogo textual», Peña Labra. Pliegos de Poesía, 55, sen paxinar.

GonzÁlez Herrán, José Manuel (I999): «Rosalía de Castro en la literatura española de su tiempo: Cien años de recepción crítica (1864-1960)», en Rosario Álvarez / Dolores Vilavedra (eds.), Cinguidos por unha arela común. Homenaxe ó profesor Xesús Alonso Montero, Santiago de Compostela, Universidade, II, 665-676.

González Herrán, José Manuel (2004): «Presencia de Curros y Doña Emilia (cincuenta años después)», en Xesús Alonso Montero / Henrique Monteagudo / Begońa Tajes Marcote (eds.), Actas do I congreso internacional Curros Enríquez e o seu tempo, Santiago de Compostela, Consello da Cultura Galega, II, 123-153.

GonZález Herrán, José Manuel (20 I 2): «Marcelino Menéndez Pelayo y el regionalismo literario montañés», Monteagudo, 3a época, 17, 73-85. 
Laverde Ruiz, Gumersindo (i 868): «Poesías de doña Robustiana Armiño (Oviedo, 1851)», en Ensayos críticos sobre filosofía, literatura e instrucción públicas españolas, Lugo, Imprenta de Soto Freire, 21-37.

Mayoral, Marina (1974): La poesía de Rosalia de Castro, Madrid, Gredos.

Menéndez Pelayo, Marcelino (1942): «Don Evaristo Silió y Gutiérrez», en Edición Nacional de las Obras Completas de Menéndez Pelayo, Estudios y discursos de crítica histórica y literaria, vol. VI, Escritores montañeses. [Ed. Enrique Sánchez Reyes]. Santander, CSIC-Aldus, 243-267.

Menéndez Pelayo, Marcelino (1982): Epistolario. I. [Ed. Manuel Revuelta Sañudo]. Madrid, Fundación Universitaria Española.

MenÉndez Pelayo, Marcelino (1983): Epistolario. IV. [Ed. Manuel Revuelta Sañudo]. Madrid, Fundación Universitaria Española.

Murguía, Manuel (I 857): «Variedades» [recensión de La flor], La Iberia, Madrid, 12-V-1857; en Alonso Montero, 1985, 171-176.

Pardo Amado, Diego (20 Io): «Un discurso clave no proceso de canonización da obra de Rosalía de Castro: La poesía regional gallega (1885) de Emilia Pardo Bazán», Madrigal. Revista de Estudios Gallegos, 13, 89-95.

PARdo BazÁn, Emilia (1973): «La poesía regional gallega. Discurso presidencial leído en la velada que para honrar la memoria de Rosalía Castro ha celebrado el Liceo de Artesanos de La Coruña el día 2 de septiembre de 1885», en De mi tierra [1888]; recogido en Obras completas, III. Cuentos / Crítica literaria (selección). Êdición de Harry L. Kirby Jr]. Madrid, Aguilar, 671-689.

Peers, Edgard Allison (1940): The History of the Romantic Movement in Spain, Cambridge, Cambridge University Press. Trad. Historia del movimiento romántico español, Madrid, Gredos, 1954.

Poullain, Claude H. (1980): «Doble perspectiva de Rosalía», Grial, 70, 423-424.

Rodríguez, Francisco (20 I I): Rosalía de Castro, estranxeira na súa patria (a persoa e a obra de onte a hoxe), [A Coruña], AS-PG.

Ruiz Aguilera, Ventura (i 864): [sen título], El Museo Universal, Madrid, 22 (20-V-1864) e 23 (5-VI-1864).

Tamayo, Manuel (i885): [sen título; «lo reproduce E. Carré Aldao en BRAG, 192 (1-III-1927), p. 296»]; en Alonso Montero, I985, 296.

Unamuno. Miguel de (I 9I 2): «Discurso en los Juegos Florales de Pontevedra (20-VIII-1912)», reproducido en Obras completas, VII, Madrid, Afrodisio Aguado, 1958, 815-817. 
